\title{
Evaluation of Choroidal Changes During Pregnancy
}

\author{
Asmaa A. Mohammed, Heba M. Abdelrahman, Mona M. Aly
}

Department of Ophthalmology, Faculty of Medicine (For Girls), Al-Azhar University, Cairo, Egypt

Corresponding author: Asmaa Abdullah Mohammed, Mobile: 01288569553; Email: first220dr@gmail.com

\begin{abstract}
Background: During pregnancy, various physiological changes occur in almost all organs of the body including the eyes. Increased blood volume and cardiac output results in ocular blood flow increase. Consequently, the choroid is a highly vascular tissue; any local or systemic pathology affecting the vasculature could also affect the choroid.

Objective: The aim of the study was to report and evaluate choroidal changes in healthy pregnant women, pregnant women with gestational diabetes mellitus (GDM), and pregnant women with gestational hypertension (GH) and to compare the measured parameters with those of healthy non-pregnant women.

Patients and Methods: This prospective comparative study comprised 180 eyes of 90 women divided into 4 groups; Group 1(control): 30 healthy non-pregnant females, Group 2 (Low risk pregnancy): 30 healthy pregnant females $\geq 24$ weeks of gestation, Group 3 and 4 (high risk pregnancy): each consisted of 15 pregnant females $\geq 24$ weeks of gestation with GDM or GH. All four groups were age-matched. Choroidal thickness (CT) was measured using enhanced depth imaging spectral domain optical coherence tomography at seven different locations.

Results: CT increased significantly in healthy pregnant females (third trimester) compared to control group and decreased significantly in high risk pregnant females compared to healthy pregnant and non-pregnant females.

Conclusion: Reporting changes in CT during pregnancy may give valuable data to interpret pregnancy-related ocular pathologies.
\end{abstract}

Keywords: Choroidal thickness, pregnancy, enhanced depth imaging optical coherence tomography

\section{INTRODUCTION}

Pregnancy is a natural state of physiological stress to the whole body. Each system of the body in a pregnant lady behaves in a different way from a nonpregnant state ${ }^{(\mathbf{1})}$. One of the most important organs affected by pregnancy-induced physiological changes is the eye such as temporary variation in refractive error, decrease in intraocular pressure (IOP) and reactive changes in the retinal vessels ${ }^{(2)}$.

Pregnancy may worsen pre-existing conditions such as diabetic retinopathy and result in the manifestation of major complications. Pathological changes during pregnancy that did not exist before have also been reported such as eclampsia-associated retinopathy and central serous chorioretinopathy ${ }^{(2)}$.

A variety of important changes in the cardiovascular system occurs starting early in pregnancy. These changes include increase in the cardiac output and heart rate. As early as the first trimester of pregnancy; progressive increase in the blood volume occurs mediated by an increase in the renin-angiotensin-aldosterone system. Hormonal changes lead to dilatation of the blood vessels. Peripheral vasodilatation leads to fall in systemic vascular resistance, which is accompanied by an increase in vascular capacity; as a result, the blood flow to many organs increases ${ }^{(3)}$.

The choroid is a vascular tissue that has an important role in providing oxygen and nutrients to the retinal pigment epithelium (RPE), outer retinal layers, avascular fovea and part of the optic nerve. The blood flow per unit weight of choroid is higher than that of any other tissue in the body (about 20 to 30 times greater than that of the retina) accounting for more than $70 \%$ of the blood flow in the eye. So, any changes of the choroid may lead to ocular problems ${ }^{(\mathbf{1}, 2,4)}$.

The development of the enhanced depth imaging optical coherence tomography (EDI-OCT) has enabled the visualization and measurement of the anatomical features of the choroid. It decreases signal strength posterior to the RPE, hence increasing image resolution of the choroid dramatically. This method of imaging is performed with Spectral Domain (SD) OCT instruments focused on deeper ocular structures, such as the choroid ${ }^{(2,5)}$.

The aim of the current study was to evaluate choroidal changes in healthy pregnant women, pregnant women with gestational diabetes mellitus (GDM), and pregnant women with gestational hypertension $(\mathrm{GH})$ and to compare the measured parameters with those of healthy non-pregnant women.

\section{PATIENTS AND METHODS}

This prospective comparative study included a total of 120 eyes of 60 pregnant women and 60 eyes of 30 age-matched healthy non-pregnant females attending at the Ophthalmology and Obstetrics and Gynecology Departments and Clinics of Al-Zahraa, Al-Azhar University Hospital. This study was conducted between July 2018 and January 2019. A written informed consent from all the subjects and approval of the Ethics Board of Al-Azhar University were obtained. This study was conducted in accordance with the Declaration of Helsinki guidelines. 
The included subjects were divided into four groups; Group 1 (control) consisted of 60 eyes of 30 healthy non-pregnant females with no ocular or systemic diseases, Group 2 (Low risk pregnancy) consisted of 60 eyes of 30 healthy pregnant females $\geq 24$ weeks of gestation with no pregnancy-related and/or systemic diseases, Group 3 consisted of 30 eyes of 15 pregnant females $\geq 24$ weeks of gestation with GDM and Group 4 consisted of 30 eyes of 15 pregnant females $\geq 24$ weeks of gestation with GH. Group 3 and 4 comprised high risk pregnancy. The age of the included female participants ranged from 18-35 years for all groups. Eyes of each participant, fulfilling all the inclusion criteria and none of the exclusion criteria, designated as the study eyes.

\section{Exclusion Criteria}

Ocular exclusion criteria: high spherical $> \pm 3$ diopters or cylindrical > 2diopters refractive errors, IOP higher than $21 \mathrm{mmHg}$, dense media opacities, history of uveitis, or any other preexisting ocular pathology, ocular trauma, previous intraocular surgery or laser therapy.

Systemic exclusion criteria: history of systemic disease; such as hypertension, diabetes mellitus, cardiovascular diseases, renal insufficiency or any systemic diseases or medications affecting the eyes; the use of oral contraceptive medications, multiple pregnancies, and the development of preeclampsia. Participants with history of smoking were also excluded.

\section{All participants were subjected to:}

A complete medical history including gestational age based on the precise date of the last menstrual period was obtained. Blood sugar was recorded. Systolic blood pressure (SBP) and diastolic blood pressure (DBP) were measured for each participant in the setting position.

The mean arterial blood pressure (MABP) was calculated according to the formula $\mathrm{MABP}=2 / 3 \mathrm{DBP}$ $+1 / 3$ SBP. By using values of blood pressure and IOP measurements, ocular perfusion pressure (OPP) was calculated using a formula $(\mathrm{OPP}=2 / 3 \mathrm{MABP}-\mathrm{IOP})^{(\mathbf{6})}$.

Each participant had a comprehensive ophthalmologic examination, including: refraction, best-corrected visual acuity, IOP measured by Goldmann applanation tonometry, slit-lamp biomicroscopic examination of the anterior segment and posterior segment (with the aid of +90 diopter non-contact lens), and fundus examination with indirect ophthalmoscope.

\section{EDI-OCT Measurements:}

Evaluation of choroidal changes was done with the patient in the setting position. Prior to the examination, all participants were fully dilated using mydriatic eye drops (tropicamide $5 \mathrm{mg} / \mathrm{mL}$ ). They also received anesthetic eye drops (benoxinate hydrochloride $0.4 \%$ ) to minimize blinking. RTVue XR Avanti system OCT device (Optovue, Inc., Fremont, USA) was used for assessment with an enhanced depth imaging mode. All OCT scans were done in the morning (10:00 am to 12:00 pm) to avoid diurnal variations of choroidal thickness (CT). Choroid was imaged with an enhanced high definition (HD) line scan using the EDI setting and fast track retinal tracking technology to minimize motion artifacts. All scans were reviewed before being included in the study for quality assessment (i.e., signal strength, loss of fixation, segmentation error, and motion artifacts). Those with image artifacts, inaccurate choroidal limits or substandard images with poor signal strength were excluded. CT was measured at seven different points; central sub-foveal and every $500 \mu \mathrm{m}$ from the center of the fovea up to $1500 \mu \mathrm{m}$ temporally and nasally. We used the white-on-black image color for better contrast between the choroid and the sclera for accurate measurements. CT was measured as the perpendicular vertical distance from the outer portion of the hyper-reflective line of the RPE to the chorio-scleral interface, manually by the help of the software in the device.

\section{Statistical Analysis}

Data were collected, revised, coded and entered to the Statistical Package for Social Science (IBM SPSS) version 23. The quantitative data were presented as mean, standard deviations (SD) while qualitative variables were presented as number and percentages. The comparison between groups regarding qualitative data was done using Chi-square test. The comparison between two independent groups with quantitative data and parametric distribution were done using Independent t-test. While the comparison between more than two groups was done by using One Way ANOVA test, while data with non-parametric distribution were done using Kruskall -Wallis test. Spearman correlation coefficients were used to assess the correlation between two quantitative parameters in the same group. The confidence interval was set to $95 \%$ and the margin of error accepted was set to $5 \%$. So, the p-value was considered significant as the following:

P-value > 0.05: Non-significant (NS), P-value < 0.05: Significant $(\mathrm{S})$ and $\mathrm{P}$-value $<0.01$ : Highly significant (HS)

\section{RESULTS}

\section{Demographic and Clinical Characteristics:}

The demographic and clinical characteristics of the participants are summarized in Table 1. The study included 180 eyes of 90 participants divided as 60 eyes of 30 healthy non-pregnant females (Control Group), 60 eyes of 30 healthy pregnant females, 30 eyes of 15 females with gestational diabetes mellitus (GDM) and 30 eyes of 15 females with gestational hypertension 
$(\mathrm{GH})$. There was no statistically significant difference in age between all groups $(\mathrm{p}=0.118)$. As regard gestational age among the three pregnant groups, there was no statistically significant difference $(\mathrm{p}=0.062)$. As expected; a statistically significant difference was observed between GH group and all other groups in terms of systolic and diastolic blood pressures $(\mathrm{p}=0.00)$. Also, there was a statistically significant difference between GDM group and all other groups in terms of random blood sugar $(\mathrm{p}=0.00)$.

Intra Ocular Pressure (IOP):

There was a statistically significant difference among the four groups in terms of IOP $(p=0.00)$ as shown in Table 2.

Table (1): Comparison between four groups as regard age, gestational age, systolic BP, diastolic BP, MABP (mean arterial blood pressure) and RBS (random blood sugar)

\begin{tabular}{|c|c|c|c|c|c|c|c|c|}
\hline & Control & Healthy & \multirow{2}{*}{$\begin{array}{c}\text { GDM } \\
\text { group (3) }\end{array}$} & \multirow{2}{*}{$\begin{array}{c}\text { GH } \\
\text { group } \\
(4)\end{array}$} & \multirow{2}{*}{$\begin{array}{c}\text { Test } \\
\text { value }\end{array}$} & \multirow{3}{*}{$\begin{array}{c}P \text { - } \\
\text { value }\end{array}$} & \multirow{3}{*}{ Sig. } \\
\hline & & \multirow{2}{*}{$\begin{array}{l}\text { group (1) } \\
\text { No. }=60\end{array}$} & \multirow{2}{*}{$\begin{array}{c}\begin{array}{c}\text { Pregnancy } \\
\text { group (2) }\end{array} \\
\text { No. }=60\end{array}$} & & & & & \\
\hline & & & & No. $=30$ & $\begin{array}{c}\text { No. }= \\
\text { 30 }\end{array}$ & & & \\
\hline Age (years) & Mean \pm SD & $28.37 \pm 3.30$ & $\begin{array}{l}26.63 \\
\pm 4.50 \\
\end{array}$ & $\begin{array}{c}29.67 \pm \\
5.39 \\
\end{array}$ & $\begin{array}{c}26.67 \pm \\
5.47 \\
\end{array}$ & 2.014 & 0.118 & NS \\
\hline $\begin{array}{l}\text { Gestational Age } \\
\text { (weeks) }\end{array}$ & Mean \pm SD & ---------------- & $\begin{array}{c}32.30 \pm \\
4.70 \\
\end{array}$ & $\begin{array}{c}34.07 \pm \\
3.37 \\
\end{array}$ & $\begin{array}{c}35.33 \pm \\
3.37 \\
\end{array}$ & 2.927 & 0.062 & NS \\
\hline Systolic (mmHg) & Mean \pm SD & $113.33 \pm 10.93$ & $\begin{array}{c}106.67 \pm \\
11.84\end{array}$ & $\begin{array}{c}113.33 \pm \\
16.76\end{array}$ & $\begin{array}{r}147.67 \\
\pm 18.21 \\
\end{array}$ & 31.874 & 0.001 & HS \\
\hline Diastolic (mmHg) & Mean \pm SD & $73.33 \pm 8.44$ & $\begin{array}{c}69.00 \pm \\
7.59\end{array}$ & $\begin{array}{c}73.33 \pm \\
10.47\end{array}$ & $\begin{array}{c}98.67 \pm \\
6.40 \\
\end{array}$ & 46.584 & 0.001 & HS \\
\hline МАBP & Mean \pm SD & $86.67 \pm 8.75$ & $\begin{array}{l}81.56 \pm \\
8.56\end{array}$ & $\begin{array}{c}86.67 \pm \\
12.15\end{array}$ & $\begin{array}{l}115.00 \\
\pm 8.61\end{array}$ & 46.163 & 0.001 & HS \\
\hline RBS (mg/dl) & Mean \pm SD & $101.67 \pm 18.48$ & $\begin{array}{c}89.97 \pm \\
11.07\end{array}$ & $\begin{array}{c}177.53 \pm \\
71.32\end{array}$ & $\begin{array}{c}98.40 \pm \\
19.38\end{array}$ & 26.955 & 0.001 & HS \\
\hline
\end{tabular}

P-value > 0.05: Non-significant; P-value < 0.05: Significant; P-value < 0.01: Highly significant

Table (2): Comparison between the four groups as regard IOP

\begin{tabular}{|c|c|c|c|c|c|c|c|c|}
\hline 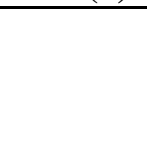 & . & $\begin{array}{c}\text { Control } \\
\text { group }(1)\end{array}$ & $\begin{array}{c}\text { Healthy } \\
\text { Pregnancy group } \\
\text { (2) }\end{array}$ & $\begin{array}{c}\text { GDM } \\
\text { group (3) }\end{array}$ & $\begin{array}{c}\text { GH } \\
\text { group (4) }\end{array}$ & Test value & P-value & Sig. \\
\hline $\begin{array}{l}\mathrm{IOP} \\
(\mathrm{mmHg})\end{array}$ & $\begin{array}{l}\text { Mean } \pm \\
\text { SD }\end{array}$ & $14.68 \pm 2.14$ & $12.37 \pm 1.86$ & $13.23 \pm 2.45$ & $12.33 \pm 1.67$ & 15.750 & 0.001 & HS \\
\hline
\end{tabular}

Evaluation of choroidal thickness in the four groups:

Regarding the comparison between the seven choroidal thickness measurements in the four groups, it was observed that the choroid always tends to be thicker in healthy pregnant females in the third trimester compared to the control group , which was statistically significant $(\mathrm{P}=0.000)$ (Figure 1). There was a statistically significant decrease in choroidal thickness in pregnant female with GDM $(\mathrm{P}=0.000)$ and in pregnant female with $\mathrm{GH}(\mathrm{P}=0.000)$ compared to both healthy pregnant and healthy non-pregnant females (Figure 2). All measurements and p-values are shown in Table 3.

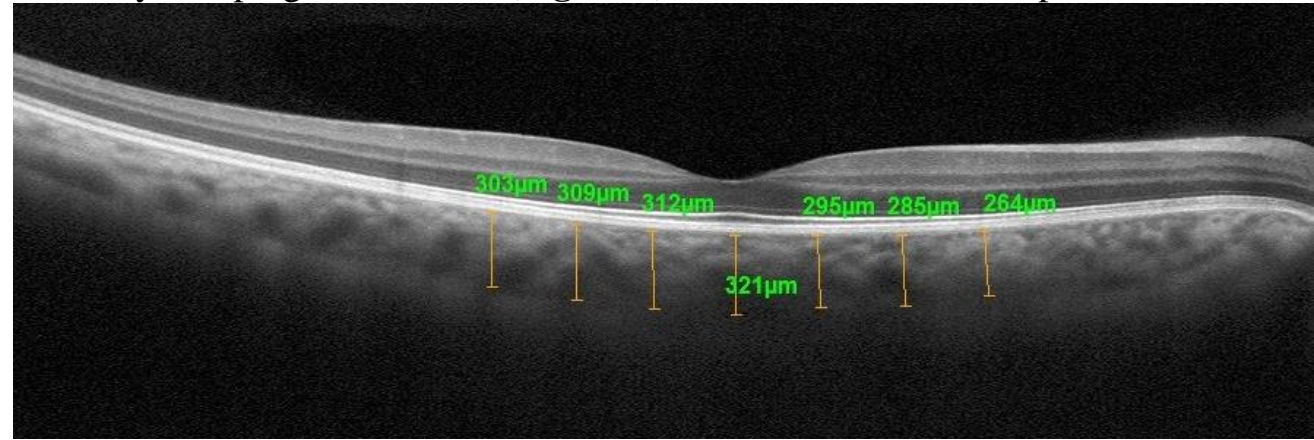

Figure 1: EDI-OCT image with the seven CT measurement points in a healthy pregnant woman. 


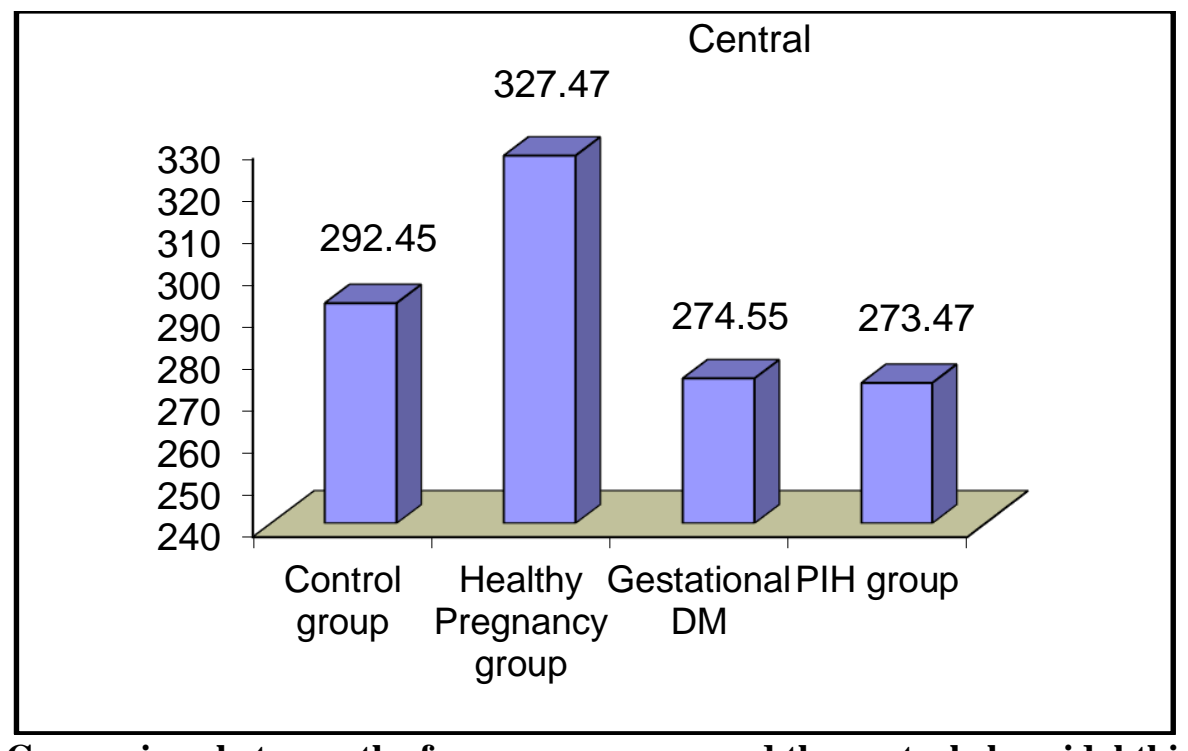

Figure 2: Comparison between the four groups as regard the central choroidal thickness.

Table (3): Comparison between the four groups as regard central, nasal 500, nasal 1000, nasal 1500, temporal 500, temporal 1000 and temporal 1500 choroidal thickness.

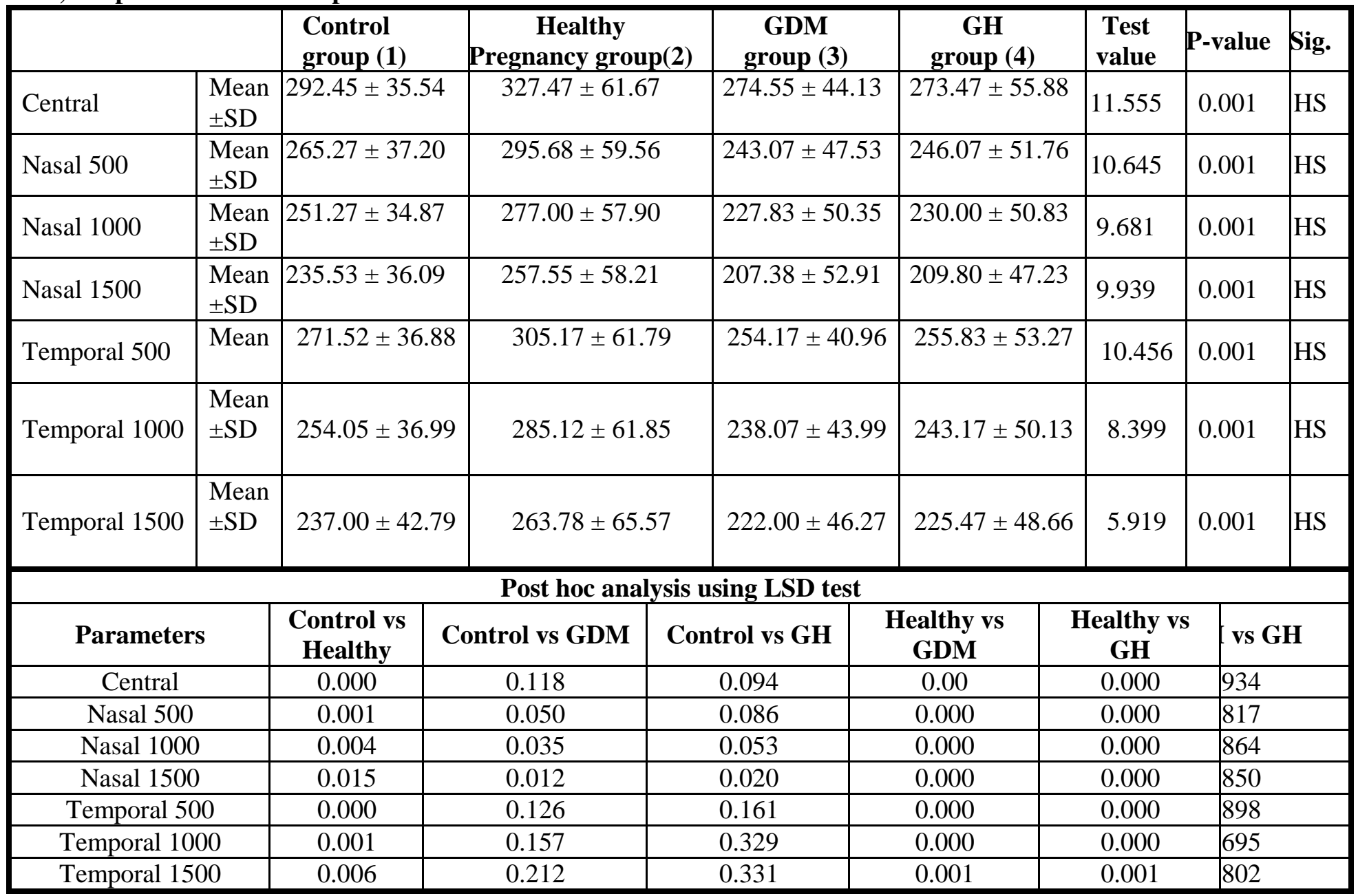

Ocular Perfusion Pressure (OPP):

There was a statistically significant difference between Group $4(\mathbf{G H})$ and the other groups in terms of OPP as shown in Table 4. 
Table (4): Comparison between the four groups as regard ocular perfusion pressure.

\begin{tabular}{|c|c|c|c|c|c|c|c|}
\hline $\begin{array}{c}\text { Ocular } \\
\text { perfusion } \\
\text { pressure }\end{array}$ & $\begin{array}{c}\text { Control } \\
\text { group (1) }\end{array}$ & $\begin{array}{c}\text { Healthy } \\
\text { Pregnancy group (2) }\end{array}$ & $\begin{array}{c}\text { GDM } \\
\text { group (3) }\end{array}$ & $\begin{array}{c}\text { GH } \\
\text { group (4) }\end{array}$ & $\begin{array}{c}\text { Test } \\
\text { value }\end{array}$ & P-value \\
\hline Mean \pm SD & $43.09 \pm 5.66$ & \multicolumn{2}{|c|}{$42.00 \pm 5.95$} & $44.54 \pm 8.73$ & $64.33 \pm 6.01$ & 93.715 & 0.001 \\
\hline \multicolumn{7}{|c|}{ Post hoc analysis using LSD test } \\
\hline Parameters & $\begin{array}{c}\text { Control vs } \\
\text { Healthy }\end{array}$ & Control vs GDM & $\begin{array}{c}\text { Control vs } \\
\text { GH }\end{array}$ & $\begin{array}{c}\text { Healthy } \\
\text { vs GDM }\end{array}$ & Healthy vs GH & $\begin{array}{c}\text { GDM } \\
\text { vs GH }\end{array}$ \\
\hline $\begin{array}{c}\text { Ocular perfusion } \\
\text { pressure }\end{array}$ & 0.353 & 0.313 & 0.000 & 0.078 & 0.000 & 0.000 \\
\hline
\end{tabular}

Correlation between the Central Sub-foveal CT and OPP:

There was no correlation between the central sub-foveal choroidal thickness and ocular perfusion pressure in all groups as shown in Table 5.

Table (5): Correlation between central sub-foveal choroidal thickness and ocular perfusion pressure in all groups

\begin{tabular}{|l|c|c|c|c|}
\hline & Mean OPP & $\begin{array}{c}\text { Mean subfoveal } \\
\text { choroidal thickness }\end{array}$ & \multicolumn{2}{|c|}{ Central } \\
\cline { 3 - 5 } & & & r & p-value \\
\hline Control group & & $292.45 \pm 35.54$ & 0.246 & 0.058 \\
\hline Healthy Pregnancy group & $43.09 \pm 5.66$ & $327.47 \pm 61.67$ & 0.229 & 0.078 \\
\hline GDM & $44.54 \pm 8.73$ & $274.55 \pm 44.13$ & 0.302 & 0.111 \\
\hline GH group & $64.33 \pm 6.01$ & $273.47 \pm 55.88$ & 0.305 & 0.101 \\
\hline All cases & & & 0.022 & 0.765 \\
\hline
\end{tabular}

r: Correlation coefficient

\section{DISCUSSION}

Pregnancy causes various hemodynamic and cardiac changes to the human body and these changes continue until birth. Decreased peripheral vascular resistance, increased cardiac output and decreased blood osmolality are some of these changes. Pregnancy also affects the eye. These effects may be physiological or pathological ${ }^{(7-10)}$. Increased cardiac output and blood volume resulted in increased ocular blood flow. Therefore, the choroid is one of the most affected ocular tissues in this condition because of its dense vascular structure and high blood flow ${ }^{(11)}$. It differs from the retina; choroid has limited auto-regulation of its blood flow and it has intense autonomic innervations ${ }^{(5)}$.

In the literature, there are many studies discussing the choroidal thickness in pregnancy ${ }^{(11-13)}$. Since they have reported different results, there is no consensus on the relationship between choroidal thickness and pregnancy. CT during pregnancy is influenced by major factors such as; the age of the patient, systolic and diastolic blood pressure, ocular perfusion pressure and other unknown factors ${ }^{(\mathbf{1 2}-15)}$.

In the current study, we considered these prementioned factors that may affect the choroidal thickness in pregnancy. Four age-matched groups were created. As pregnancy itself could lead to physiological changes in the choroid, so our control group consisted of healthy non-pregnant women (Group 1). Other groups included healthy pregnant women in the third trimester (Group 2), pregnant women in the third trimester with gestational diabetes (Group 3) and pregnant women in the third trimester with gestational hypertension (Group 4). Systolic and diastolic blood pressures and IOP were measured and ocular perfusion pressure was calculated.

Choroid thickness in pregnancy has been discussed in various studies and contradictory results were reported. Takahashi et al. ${ }^{(16)}$ and Benfica et al. ${ }^{(17)}$ conducted studies comparing CT of healthy pregnant women with healthy non-pregnant women. They have reported that there was no significant difference in choroidal thickness between both groups, while Rothwell et $a ._{.}^{(2)}$ and Ulusoy et $\boldsymbol{a l} .{ }^{(13)}$ reported that pregnant women in the third trimester had increased CT compared to the healthy non-pregnant control group; the same result was proved by our study. This may be due to pregnancy-related fluid retention in the choroid as a part of increased blood volume in the whole body ${ }^{(11)}$. Also decreased vascular resistance during pregnancy may cause increase blood flow through many organs, for example, the uterus, kidneys, and skin ${ }^{(7-9)}$. As the choroid, is a tissue with dense vascular structure and high blood flow ${ }^{(11)}$, it should respond by an increase in its thickness to these changes.

Our study also reported that there was a significant decrease in CT in pregnant females with GDM $(\mathrm{P}=0.000)$ compared to both healthy pregnant and healthy nonpregnant females; while Benfica et $\boldsymbol{a l} \cdot{ }^{(5)}$ and Acmaz et $\boldsymbol{a l} .^{(\mathbf{1 8})}$,stated that there was no significant difference 
between the GDM group and the healthy pregnant group as regard to CT measurements. In contrast to our study, Acmaz et al. ${ }^{(18)}$ stated that CT was significantly thicker in pregnant women with GDM compared to nonpregnant women.

Gestational hypertension $(\mathrm{GH})$ is diagnosed in women whose blood pressure reaches $\geq 140 / 90 \mathrm{mmHg}$ for the first-time during pregnancy (after 20 weeks gestation), but without proteinuria ${ }^{(19)}$. We reported a significant decrease in choroidal thickness in pregnant female with $\mathrm{GH}(\mathrm{P}=0.000)$ compared to both healthy pregnant and healthy non-pregnant females. To the best of our knowledge, there were no previous reports on CT in pregnant women with gestational hypertension; hence the present study is the first study to report the effect of gestational hypertension on CT.

We excluded patients who developed preeclamsia. Ataş $\boldsymbol{e t}$ al. ${ }^{(20)}$ and Sayin $\boldsymbol{e t}$ al. ${ }^{(17)}$ studied the effect of preeclampsia on CT and reported that the choroid was significantly thicker in preeclamptic women and healthy pregnant women than in healthy non-pregnant women. But the increase in CT in preeclampsia was lower than the healthy pregnant women. They attributed this lower rise in choroidal thickness in preeclampsia to the markedly increased systemic vascular vasospasm secondary to preeclampsia ${ }^{(20)}$.

The variability of results may be caused by several factors. Studies differ with respect to such variables as number of patients examined, patients' age, gestational age when performing the examination and differences related to the refraction status of the women enrolled into the study. A comprehensive study evaluating the subfoveal choroidal thickness (SFCT) in more than three thousands adult Chinese subjects showed that the SFCT varies with ocular biometric parameters, refractive error, and age. SFCT is higher in younger individuals, in shorter eyeballs, in eyes with a deeper anterior chamber, thicker lens, flat retina, and better best corrected visual acuity (BCVA). They recommended that these factors should be considered while performing choroidal thickness measurements ${ }^{(21)}$. So, in the current study we excluded eyes with high refractive errors and the enrolled subjects were age-matched and the all pregnant ones were in their third trimester.

Due to daily fluctuations in choroidal thickness, the time at which the examination is performed should be the same in all studies. Iwase $\boldsymbol{e t}$ al. ${ }^{(22)}$, in their study, found that SFCT was subjected to significant diurnal variations. It was observed that during the day SFCT decreases with the lowest values noted at $3 \mathrm{pm}$, whereas at night an increase in the choroidal thickness was observed. So, in the current study CT was measured at fixed time of the day between 10 am and $12 \mathrm{pm}$.

Owing to the relationship confirmed between the hormonal effect and the CT, the phase of the menstrual cycle of women in the control group should be considered ${ }^{(23)}$. Dadaci et al. ${ }^{(24)}$ referred to the phase of the menstrual cycle of women in the control group. They showed that CT of the pregnant women was thicker than CT of the control group (age-matched healthy women during the follicular phase of the menstrual cycle); although it did not reach a statistically significant level $(p>0.05)$. In the current study, we didn't select women in the control group according to the phase of the menstrual cycle. This could explain the different results with the previously mentioned study.

The differences between available studies may also be caused by the equipment used for the examination. In our study, we used RTVue XR Avanti system OCT device that has an EDI mode for more accurate assessment.

Blood flow through the blood vessels depends on perfusion pressure. OPP is considered to be the driving force of blood to circulate through the intraocular vasculature $^{(25)}$. The degree of perfusion is influenced by the resistance to flow, which is a function of the vessel caliber. The OPP is the difference between arterial and venous BP. In the eye the venous pressure is roughly equal to IOP. As such, the OPP can be estimated as the difference between the arterial pressure and $\mathrm{IOP}^{(6)}$.The mean arterial blood pressure (MABP) was calculated using the following formula: $\mathrm{MABP}=2 / 3 \mathrm{DBP}+1 / 3 \mathrm{SBP}$; and accordingly, OPP was obtained using the following relation: $\mathrm{OPP}=2 / 3 \mathrm{MABP}-\mathrm{IOP}^{(6)}$. In our study, the OPP was significantly higher in $\mathrm{GH}$ group. As blood pressure is a component of OPP; it would be expected that higher OPP was related to a higher blood pressure.

In a study conducted by Kim et al. (26) showed a statistically significant relationship between subfoveal CT and OPP in the examined young healthy individuals.

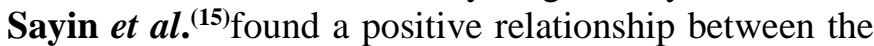
OPP and CT in pregnant women. Greene et al. (27) compared choroidal thickness in first, second and third trimester in healthy pregnant females and correlated choroidal thickness with ocular perfusion pressure. They have reported that there was a significant decrease in choroidal thickness in the 3rd trimester compared to those in the 1st and 2nd trimesters and healthy subjects. Also, there was an increase in choroidal thickness during the 2nd trimester but this increase was not statistically significant. They also reported that there was no significant correlation between choroid thickness and OPP; the same result was reported by our study.

Our study has some limitations, such as the small number of participants. In addition, we analyzed choroid characteristics only in the third trimester of pregnancy. Some authors described thicker choroids specifically at first or second trimesters ${ }^{(25)}$.Therefore, the choroidal thickness should be analyzed during the three trimesters of pregnancy and postpartum period with a large number of participants to confirm these findings.

\section{CONCLUSION}

It could be concluded that a significant increase in CT in healthy pregnant females in their third trimester compared to control group (healthy non-pregnant females) was observed and a significant decrease in CT in pregnant female with gestational diabetes and 
gestational hypertension compared to healthy pregnant and healthy non-pregnant females was reported. These findings may give valuable data to interpret pregnancyrelated ocular pathologies.

\section{REFERENCES}

1. Zhang J, Wang H, Yu Q et al. (2017): Enhanced Depth Imaging Optical Coherence Tomography: A new way measuring choroidal thickness in pregnant women. Int J Ophthalmol., 2017:8296574.

2. Rothwell RT, Meira DM, Oliveira MA et al. (2015): Evaluation of choroidal thickness and volume during the third Trimester of pregnancy using Enhanced Depth Imaging Optical Coherence Tomography: A pilot study. J Clin Diagn Res., 9(8): NC08-11.

3. Roskal-Wałek J, Laudańska-Olszewska I, Biskup M et al. (2017): Choroidal thickness in women with uncomplicated pregnancy: Literature Review. Biomed Res Int., 2017:5694235.

4. Ferro Desideri L, Barra F, Ferrero S et al. (2018): Choroidal thickness changes measured by enhanced depth imaging optical coherence tomography in third trimester pregnant women. Int J Retina Vitreous, 4: 14.

5. Benfica CZ, Zanella T, Farias LB et al. (2018): Macular choroidal thickness in pregnant women with type 1, type 2 and gestational diabetes mellitus measured by spectral-domain optical coherence tomography. Clin Ophthalmol., 12: 1259-1265

6. Costa VP, Harris A, Anderson D et al. (2014): Ocular perfusion pressure in glaucoma. Acta Ophthalmol., 92(4): 252-266.

7. Thornburg KL, Jacobson SL, Giraud GD et al. (2000): Hemodynamic changes in pregnancy. Semin Perinatol., 24(1): 11-14.

8. Samra KA (2013): The eye and visual system in pregnancy, what to expect? An in-depth review. Oman J Ophthalmol., 6(2): 87-91.

9. Dinn RB, Harris A, Marcus PS (2003): Ocular changes in pregnancy. Obstet Gynecol Surv., 58(2): 137-144.

10. Sheth BP, Mieler WF (2001): Ocular complications of pregnancy. Curr Opin Ophthalmol., 12(6): 455-463.

11. Wałek JR, Olszewska IL , Biskup M (2017): Choroidal thickness in women with uncomplicated pregnancy. Biomed Res Int., 10:1-8.

12. Goktas S, Basaran A, Sakarya Y et al. (2014): Measurement of choroid thickness in pregnant women using enhanced depth imaging optical coherence tomography. Arq Bras Oftalmol., 77(3): 148-151.

13. Ulusoy DM, Duru $N$, Ataş $M$ et al. (2015): Measurement of choroidal thickness and macular thickness during and after pregnancy. Int J Ophthalmol., 8(2): 321-325.

14. Kara N, Sayin N, Pirhan D et al. (2014): Evaluation of Subfoveal Choroidal thickness in Pregnant Women Using Enhanced Depth Imaging Optical Coherence. Curr Eye Res., 39(6): 642-647.
15. Sayin N, Kara N, Pirhan D et al. (2014): Subfoveal Choroidal thickness in Preeclampsia: comparison with normal pregnant and nonpregnant women. SeminOphthalmol., 29(1): 11-17.

16. Takahashi J, Kado M, Mizumoto $K$ et al. (2013): Choroidal thickness in pregnant women measured by enhanced depth imaging optical coherence tomography. Jpn J Ophthamol., 57(5): 435-439.

17. Benfica CZ, Zanella T, Farias LB et al. (2018): Comparative analysis of choroidal thickness in third trimester pregnant women. Int J Retina Vitreous, 4:6.

18. Acmaz G, Atas M, Gulhan A et al. (2015): Assessment of Macular Peripapillary Nerve Fiber Layer and Choroidal Thickness Changes in Pregnant Women with Gestational Diabetes Mellitus, Healthy Pregnant Women, and Healthy Non-Pregnant Women. Med Sci Monit., 21: 1759-1764.

19. Watanabe $K$, Naruse $K$, Tanaka $K$ et al. (2013): Outline of definition and Classification of "Pregnancy induced Hypertension (PIH)". Hypertens Res Pregnancy, 1(1): 3-4

20. Ataş M, Acmaz G, Aksoy $\mathrm{H}$ et al. (2014): Evaluation of the macula, retinal nerve fiber layer and choroid in preeclampsia, healthy pregnant and healthy nonpregnant women using spectral-domain optical coherence tomography. Hypertens Pregnancy, 33(3): 299-310

21. Wei WB, Xu L, Jonas JB et al. (2013): Subfoveal choroidal thickness: The Beijing eye study. Ophthalmology, 120 (1): 175-180.

22. Iwase T, Yamamoto $K$, Ra $\mathbf{E}$ et al. (2015): Diurnal variations in blood flow at optic nerve head and choroid in healthy eyes: diurnal variations in blood flow. Medicine (Baltimore), 94(6):e519.

23. Ulas F, Dogan U, Duran B et al. (2013): Choroidal thickness changes during the menstrual cycle. Curr Eye Res., 38 (11): 1172-1181.

24. Dadaci Z, Alptekin H, Oncel Acir N et al. (2015): Changes in choroidal thickness during pregnancy detected by enhanced depth imaging optical coherence tomography. Br J Ophthalmol., 99(9):1255-1259.

25. Schmidl D, Garhofer G, Schmetterer L (2011): The complex interaction between ocular perfusion pressure and ocular blood flow-Relevance for glaucoma. Exp Eye Res., 93(2): 141-155.

26. Kim M, Kim SS, Kwon HJ et al. (2012): Association between choroidal thickness and ocular perfusion pressure in young, healthy subjects: enhanced depth imaging optical coherence tomography study. Invest Ophthalmol Vis Sci., 53(12): 7710-7717.

27. Greene B, Capkin M (2018): Evaluation of choroid thickness and ocular perfusion pressure in healthy nonpregnant women and healthy pregnant women during first, second and third trimesters. Optom Open Access, 3:1. 